\title{
Developing Learners' Top-Down Processing Skills in Listening
}

\author{
Lilit Bekaryan \\ Yerevan State University
}

\begin{abstract}
Listening is the first receptive skill that we develop as human beings, and it helps us improve other skills and gain confidence as language learners. In the English language classroom, learners find listening tasks particularly frustrating and challenging for a range of reasons. The present research addresses ways of developing learners' top-down processing skills, such as making predictions about the target text, guessing the context and using contextual clues to infer meaning.
\end{abstract}

Key words: receptive skills, listening comprehension, top-down processing, listener-oriented strategies, listening tasks.

\section{Introduction}

Listening is the most frequently used language skill, as it takes up 40-50\% time spent on communication (Rivers in Gilman and Moody 1984:331, quoted in Vandergrift 2002). Obviously, listening plays a significant role in the classroom as the primary medium of learning in all stages. Long before, listening was thought to be a passive skill along with reading. However, modern research shows that listening is a goal-oriented activity, requiring a lot of mental efforts and strategies (Thornbury 2006:123).

The present research focuses on developing University students' top-down processing skills. This choice is due to my teaching experience in a non-English speaking country, Armenia, where listening in the classroom is perceived to be a passive skill, associated with reinforcing language input. About $85 \%$ of listening tasks in Armenian course-books instruct the learners to listen to every single word in the text and memorize a lot of information. These kinds of activity reduce the learners' motivation, as their success is measured by the number of correct responses they give and as pointed out by researchers provide them with practice in listening but fail to teach the skill itself (Brown 1986:286, 
Field 1998:111). Hence, the difficulties that the learners might have experienced are addressed only in terms of the language and content, whereas little attention is paid to how challenging the spoken text is for them from the perspective of prior knowledge or experience. My classroom experience shows that learners' difficulties in the comprehension of the listening text are often due to their inability to transfer their top-down processing strategies they can effectively use in their L1 to the target language.

The present paper seeks to study ways of helping adult learners develop their top-down processing skills when completing listening tasks in the classroom.

\section{Bottom-up and Top-down Processes in Listening}

Richards identifies bottom-up and top-down processes for processing spoken discourse. When processing spoken discourse bottom-up, learners make use of their knowledge of language systems, also referred to as systemic knowledge. Comprehension in this case is viewed as a process of decoding sounds, words, clauses, sentences, texts until the listener arrives at the meaning (Richards 2008:8).

Top-down processing, on the other hand, is related to using background information to understand the meaning of the spoken message. Thus, if bottomup processing goes from language to meaning, top-down processing goes from meaning to language. In this case, listeners make use of their prior knowledge about the type of discourse, situation or the context when listening to a spoken text and trying to understand it.

It is worth mentioning that successful listeners tend to integrate both processes when listening to spoken texts. As Vandergrift argues, listening comprehension is not either top-down or bottom-up processing, but an interactive process where listeners use both prior knowledge and linguistic knowledge (Vandergrift 2002).

Top-down listening strategies are listener-oriented and involve the listener's knowledge, sometimes referred to as "inside the head information" or the background information (Hedge 2014:232) as compared to the information comprised in the text. Background knowledge consists of the situation, the context and the co-text. The listener first activates his/her background knowledge of the topic (also known as schemata), then the situation or the context, afterwards the type of text and then the language. 
Schematic knowledge is the knowledge the listener already has about the world and about certain types of discourse (Anderson \& Lynch 1988:13). Schematic knowledge can vary across cultures and people. For example, the sentence "She has posted new photos online" might confuse my grandmother, who does not have the required schemata for the social media. Hence, if listeners are not familiar with the incoming information, they cannot have the necessary schemata summoned and will have to rely only on their systemic knowledge, i.e. the knowledge of the language.

Contextual knowledge is the information the listener has about the place where the listening takes place. In other words, besides the general knowledge of the world, language users need to have knowledge about the current communicative situation (Van Dijk 2005:72). Contextual knowledge makes many listening situations predictable, as they follow certain routines. For instance, when my daughter's teacher invites me to her office and I can see the grade report on her desk, I understand that she is going to discuss her learning progress with me.

Obviously, contextual and systemic knowledge can make comprehension easy. When listeners are familiar with the content of the material, they can employ their background knowledge to make predictions.

Hedge (2014:233) mentions three types of schemata used in top-down processing, namely content schemata, formal schemata, and script. Content schemata refers to general world knowledge, socio-cultural knowledge, or knowledge of the topic. Scripts are defined as interactions where the speech follows a set pattern to some extent. For instance, in a consumer-salesperson exchange in the context of a mobile phone purchase, the salesperson will often ask a series of set questions. Formal schemata indicates the knowledge people share about the overall structure of speech events, e.g. cause-effect, problemsolution (Ibid: 232). It is referred to as textual schemata by Schmitt (2010:184) who highlights its role in identifying the genre of the listening text, e.g. we know that 'once upon a time' signals the start of a fairy tale. Knowing the genre of the listening text makes it easier for adults to engage in top-down processing strategies, such as predicting and inferring from the text. 


\section{Listening in the Lesson}

Current researchers (Cattlin 2014:7.2; Richards, 2008:10; Wilson 2012:60) suggest that a listening lesson should be divided into pre-listening, whilelistening and post-listening stages.

The pre-listening part of the listening lesson prepares the learners for what they are going to hear and can comprise a prediction or activating schemata stage, during which the teacher generates the learners' interest in the topic and activates their schematic knowledge. In the pre-listening stage, the teacher can also pre-teach the vocabulary that she believes will impede with the learners' overall understanding of the text.

In while-listening stage the learners focus their attention on the listening text and develop their listening comprehensions skills. In this stage, learners complete tasks that develop their top-down and bottom-up processing skills. They might, for instance listen to the segment of the story to check if their prediction about the hero's background was right. Top-down listening activities specific to the while-listening part are listening for gist, when the learners have to listen to understand the main ideas, topic and setting of the text and inferencing or inferring, as referred to by J.J. Wilson, when learners make deductions making analogies to the situations they can recognize (Wilson 2012:84).

In post-listening stage, the learners will be introduced to the target language inherent in the listening tasks and activities, as well as develop their summarizing skills, for instance by sharing the story from their own perspective or discuss its possible continuation with their partner.

\section{Learner Issues and Teaching Suggestions}

When discussing the problems inherent in listening comprehension, Cherry (1957) as quoted in Hedge (2014:237) introduces the term 'uncertainty'. He goes on identifying several categories of uncertainties that influence the listener's comprehension of the message. He believes the first uncertainty to be related to the confidence in the language. When listening to a message in the target language, language learners tend to have unrealistic expectations, anticipating to understand every single word comprised in the message instead of aiming for general comprehension made available by the context. Dwelling on this, Hedge notes that learners' anxiety can be exacerbated by a classroom procedure which does not contextualize the text or prepare the topic by 
activating the required schemata. In other words, tasks requesting that the students should listen to the text and then proceed to answer the questions can not only cause unnecessary tension and strain for the students, but also impede their ability to perform well in the respective task (2000:237). An argument based on my own classroom observations is that this kind of tasks usually test the learners' lsitening skills but fail to teach them anything. To tackle this problem and to build confidence in the learner's ability to understand, Hedge suggests the teacher taking the pace and length of the listening activity into consideration (2000:237).

Cherry claims the second uncertainty to be due to the structure of authentic speech, fraught with repetitions, pauses, incomplete sentences, as well as a larger degree of colloquial language. Hedge (2000:240) puts forward strong arguments for using slow, clear recordings of Standard English with familiar accents, especially in the earlier stages of language learning. At the same time, she highlights the importance of developing the ability to deal with listening outside the classroom and familiarizing the learners with the variation in pace and pronunciation, along with learning language strategies and vocabulary development (2000:240). In this respect, having learners exposed to authentic language materials can aid both the retention of vocabulary items in the context and encourage the learners to identify the prosodic features inherent in the communication of native speakers.

Cherry identifies gaps in the message as another reason for uncertainties to take place. An important strategy to address these gaps would be asking the learners to predict what the speaker will say next, by attracting their attention, for instance, to the transitions and discourse markers in the message.

Conversational strategies, such as nodding to signal agreement and asking for clarification, when the message is not understood, can also cause uncertainties. As we know, most of the mentioned conversational strategies tend to differ across countries and cultures and might cause misunderstanding in communication.

The fifth uncertainty, according to Cherry, is the uncertainty of language, which has to do with the listener's proficiency in understanding vocabulary, grammatical structures etc. Uncertainties of content have to do with the listener's lack of background knowledge, which often makes it difficult to understand what is being said. Hedge believes that the uncertainties of content 
can be resolved in the pre-listening stage, when the learners' prior knowledge can be activated and missing prior knowledge can be introduced (2000:241).

It seems appropriate to reflect on one's teaching experience and learn which of the aforementioned 'uncertainties' underlie the problems and challenges learners experience in the classroom when completing listening tasks and whether there are any other factors that account for the learners' low performance in listening activities. It also seems useful to provide an effective solution to each of the listed problems. In the light of my English language teaching experience, I can state that out of the two receptive skills, learners find listening to be more challenging for the following reasons.

\section{a) Affective factors, such as lack of interest and concentration}

Learners find it hard to concentrate on the listening task because they are not interested in the topic and thus do not feel motivated enough to complete the listening task.

To address this problem, it will help to use listening tasks that comprise information relevant to the learners' needs. For instance, before the course starts it will be useful to conduct one-to-one or paired interviews to find out information about the learners' needs, learning styles, preferences and interests. Interviews may be done either in L2 or in the learners' native language. These kinds of proactive activity can not only address the learners' lack of motivation but also help the teacher identify the types of stimuli, which are likely to interest and attract each learner in the group.

\section{b) Problems affecting the interpretation of the spoken message}

In 1980, Underwood suggests that the learners' inability to understand the listener is not caused by their insufficient systemic knowledge but by their unfamiliarity with the context (1989:19). This happens because when having to listen in real life, students already know the context and can rely on their prior knowledge and experience to have an idea what they are going to hear, whereas in the classroom, they lack this knowledge.

In this respect, Underwood suggests providing the learners with pre-listening support to help them concentrate on what they are going to hear. This involves outlining the setting and giving background information but not telling the students too much so that the whole listening experience does not lose its value. The questions preceding a listening task can activate the learners' mental schemata about the topic of the lesson and help the learners build up their own 
expectations about the information they are going to hear. The gained knowledge gives the learners the required confidence for successful listening.

\section{c) Insufficient visual interpretation}

When engaged in face-to-face interaction in their L2, learners often rely on facial expressions and body language to interpret the cues to decipher the meaning of the message. In the classroom, when listening to audio files, they are often deprived of the opportunity to see the speaker and thus cannot rely on their interpretation of the context and the speakers' attitude.

In this respect, research highlights the relevance of visual aids and videos in contextualizing listening activities and encouraging the learners to work out the visual clues to meaning (Hedge 2014:246). Silent viewing, playing the video with the sound off using only the picture can be used in the pre-listening stage as a prediction technique to arouse students' interests, stimulate thought, and develop their skills of anticipation.

An alternative to the same activity can be freezing the picture on the screen and encouraging the learners to guess what might be happening afterwards in the story

\section{d) Scarce systemic knowledge}

In the while-listening stage, when extracting the gist, the learners might be unable to form mental representations from the spoken text due to the lack of language knowledge. This can prevent them from processing the relevant information. To address this problem, teachers are recommended pre-teaching the so-called blocking vocabulary, lexical items that are crucial to the comprehension of the message.

e) Lack of control over the pace of speech and the inability to get things repeated

In real life, learners have the opportunity to interrupt their interlocutor, asking for clarification or making the speaker repeat what they have said. When completing listening tasks in the classroom, learners believe that they might miss some important information and they cannot re-listen to it. This feeling can make the learners focus on certain words and miss the general meaning of the text. Vandergrift believes that this problem can be exacerbated particularly for lower-level listeners, who are often unable to process what they hear and focus on details instead (Vandergrift 2004:4-5).

In this respect, Lynch (1996:89) introduces the idea of paused listening tasks in the classroom. Paused listening tasks boost the learners' confidence and 
encourage the learners to talk about their mental models of the segment they have formed when listening to the message. It is worth mentioning that they do not necessarily have to be based on recorded materials, e.g. the teacher can pause when telling a story.

\section{Conclusion}

To conclude, listening skills are crucial not only to learning but real life as well. This fact encourages researchers to compare them to life skills. The frustration and anxiety, learners often experience when facing listening tasks can block their understanding and impede their further learning. Hence, it seems reasonable to encourage learners to develop top-down listening strategies reliant on the background knowledge in understanding the message.

\section{References:}

1. Anderson, A. \& Lynch, T. (1988) Listening. Oxford: OUP.

2. Brown, G. (1986) Investigating Listening Comprehension in Context. // Applied Linguistics. / Ed. by J. Hellermann and A. Mauranen. Vol. 7/3. Oxford: OUP.

3. Cattlin, M. (2014) The Art of Lesson Planning: A Handbook for Pre-Service and In-Service Teachers of English to Speakers of Other Languages. Kindle Edition.

4. Cherry, C. (1957) On Human Communication: A Review, a Survey and a Criticism. Cambridge: MIT Press.

5. Field, J. (1998) Skills and Strategies: Towards a New Methodology for Listening. // ELT Journal. / Ed. by G. Hall. Vol. 52/2 April. Oxford: OUP.

6. Hedge, T. (2010) Teaching and Learning in the Language Classroom. Oxford: OUP.

7. Lynch, T. (1996) Communication in the Language Classroom. Oxford: OUP.

8. Richards, J. (2008) Teaching Listening and Speaking: From Theory to Practice. Cambridge: CUP.

9. Schmitt, N. (2010) An Introduction to Applied Linguistics. New York: Routledge.

10.Thornbury, S. (2014) An A-Z of ELT. A Dictionary of Terms and Concepts. Oxford: Macmillan Books for Teachers. 
11.Underwood, M. (1989) Teaching Listening. N.Y.: Longman.

12.Vandergrift, L. (2002) Listening: Theory and Practice in Modern Foreign Language Competence. Available at: <https://www.llas.ac.uk/resources /gpg/67> [Accessed August 2015].

13.Van Dijk, T. (2005) Contextual Knowledge Management in Discourse Production. // A New Agenda in Critical Discourse Analysis. / Ed. by R. Wodak and P. Chilton. Amsterdam/Philadelphia: John Benjamins Publishing Company.

14. Wilson, J.J. (2012) How to Teach Listening. Essex: Pearson Education Limited.

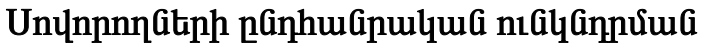 hưunıpjnıGitinh qunqugưua hungh 2 nıng}

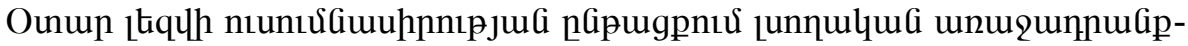

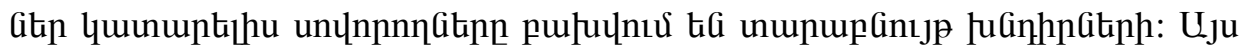

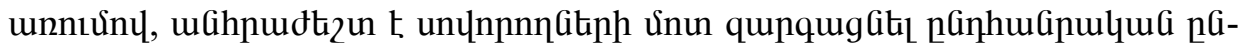

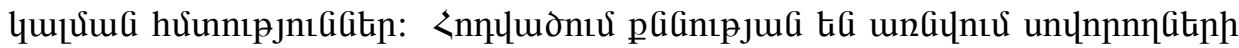

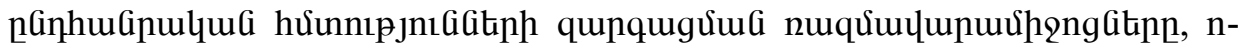

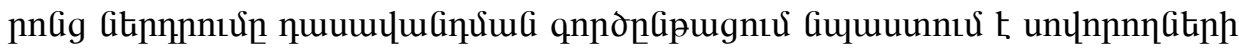

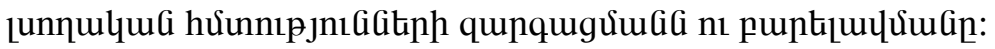

